\title{
Design Guidelines For Recycling AC Induction Motors
}

\author{
D. Ismail, K. Anayet, N. Indra, M. Dina M.M. Ahmad, A. Rosnazri \\ School of Electrical System Engineering \\ Northern Malaysia University College of Engineering \\ 01000 Kangar, Perlis, Malaysia
}

\begin{abstract}
This paper describes the design guidelines of an AC induction motors based on recycling. This explains the detail description of the induction motor or machine parts how to reuse. Technological issues arising from following machine components are covered: stator insulation, rotor insulation, stator core, rotor core, stator windings, rotor windings, bearings, shaft and frame. The design guidelines applied to induction motors and investigated in this manner should have: higher reliability and availability, lower initial and operating costs, smaller losses and environmental advantages.
\end{abstract}

Keyword: Recycle induction motors, AC machines, Motors

\section{INTRODUCTION}

The latest economic trends dictate that to be competitive with unconventional drives or energy converters of any kind, parts interchangeability and recycling should be taken into account. Furthermore, legislative efforts have begun to mandate recycling or manufacturer "take back"; therefore, consideration of these matters is a necessity. It is offered a new line of enquiry of how to construct large and small induction motors that comply with whole society needs.

The electromagnetic induction characteristics are essential features of an induction motor. Having decided unit rating, required inertia and speed, physical dimensions of a machine are selected from a number of combinations of rotor, stator (inner and outer) core diameters and core length and yet allowing rating to be obtained with economic utilization of construction materials. Normally, in large and small induction motors, the power system engineer defines the machine voltage. All these requirements must be woven into the electrical design to form the starting point for the design of mechanical structures to provide necessary interrelationships between stationary and rotating parts.

It is noted that, we add recycling guidelines, we are thinking, theoretically, of reused induction motors, or machines whose parts may be reused many times. It is definitively necessary, for achieving effective recycling to assemble and to disassemble the induction motor in a very simple manner, and to standardize, sizes, shapes and materials such as frame, core, slots and windings. Some justifications for recycling are; to standardize design procedures, construction, and specifications to diminish initial, operational and maintenance costs. Induction motors recyclable are in harmony with world tendency called "take back product" with a positive impact on the environment. ${ }^{[3]}$

Now a day the ever-increasing imbalance between the demand and supply of energy has focused our attention towards energy conservation. Numerous attempts have been made to achieve this either by harnessing energy from renewable sources or by improving the operating efficiency of devices used in generation, transmission and utilization-of electric energy. Induction motors are considered to be the main workhorse and are used in very large number in a variety of applications, which include sectors like office, home, farm and industry. Any significant design improvement of AC induction motor will, therefore, help our effort at energy conservation as well. ${ }^{[4]}$

The Recyclable Induction Motor: A recyclable induction motor is a simple one, easy to assemble and easy to disassemble its stator and rotor cores. A recyclable induction motor uses few materials; it uses materials that do not age significatively on operation, or it uses materials that can be restored "economically" to unaged specifications or it uses materials whose electrical, magnetic and mechanical characteristics improve with aging. Recyclable induction motor parts may be used "economically" later on another machine of equal or different size. A recyclable induction motor has the highest reliability and availability, the lowest initial and operating costs and the lowest losses; and could be used in a world of manufacturers and users 
ruled by standards and mechanisms that value and promote recycling, from an "economic" point of view.

When an induction motor is no longer useful to an industry or a consumer, it can be handled, generally, within following categories,

1. Discarded into the environment.

2. Placed in a permitted landfill.

3. Put to a high-value use, breaking it down into its components, melting steel, copper and aluminum.

4. Rebuilt (totally or partially), some components discarded or reused, or rebuilt motor.

5. Reused.

Categories 1 and 2 are not recycling. Categories 3, 4 and 5 may be regarded as recycling. Categories 1 and 2 damage the environment (external negative value). Categories 3, 4 and 5 create value at life end of the induction machine. ${ }^{[3]}$

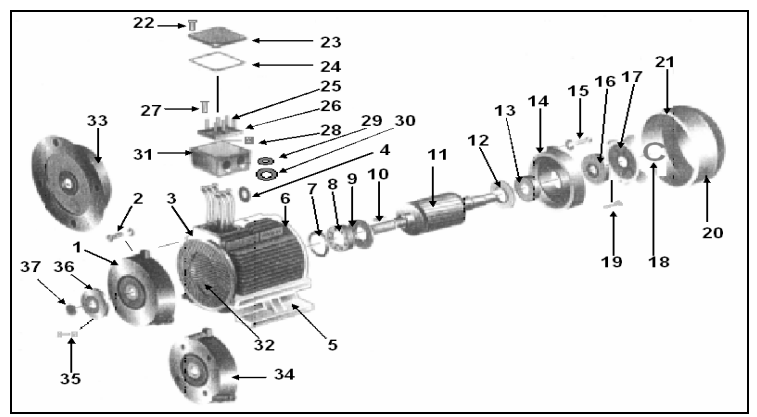

Fig. 1: Assemble and disassemble parts of three-phase squirrel cage induction motor

Design Guidelines For Recycling Ac Induction Motor: The recycling induction motor design guidelines might be stated as follows:

- Simplify parts.

- Design, both for assembly and disassembly.

- Reduce material diversity.

- Maximize usage of recyclable materials.

- Insulators should not age and should be hardened by reversible processes or its characteristics should improve with time.

- Ferromagnetic plates and conductors should not age or its characteristics should improve with time.

Manufacturers and users relations should be governed by:

a) Standards including shapes and dimensions

b) Mechanisms that allow for new machines to be made of used or rebuilt parts.
Dimensions: The initial step on the design of an induction motor requires a specification of performance. The main data needed by the design engineer are power, power factor, line voltage, starting current, frequency, number of phases, temperature rise of the windings and cores, rated speed and inertia. Design might begin with a broad dimensional study, as for example, an analysis of the output coefficient defined as:

$$
\xi_{1}=\frac{P}{D_{g}^{2} L_{c} N}
$$

Where as,

$P=$ rated power.

$D g=$ air gap diameter.

$L_{c}=$ gross stator core length .

$N=$ synchronous speed.

$\xi_{1}$ is approximately constant within certain ranges. Thus, it is possible to relate rotor volume, synchronous speed and power. Therefore, rotor and stator internal diameters can be standardized.

The stator outer diameter follows a similar relationship

$\xi_{2}=\frac{P}{D_{0}^{3} L_{c} N}$

Where as

Do $=$ stator outer diameter.

$\xi_{2}$ is approximately constant within certain ranges too. ${ }^{[5]}$

Accordingly, external stator core diameter is closely related to stator core inner diameter and rotor core outer diameter. To achieve needed power the length can be varied. Slots dimension must be standardized too, if ferromagnetic plates are to be interchanged.

Figures 2, and 3, and 4 show internal and external ferromagnetic core diameters considered.

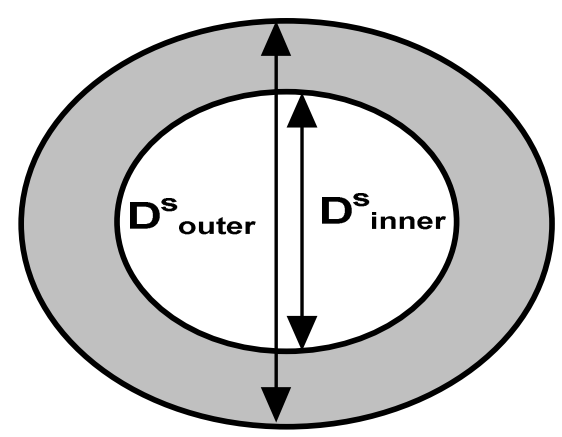

Fig. 2: Inner and outer stator core diameters. 


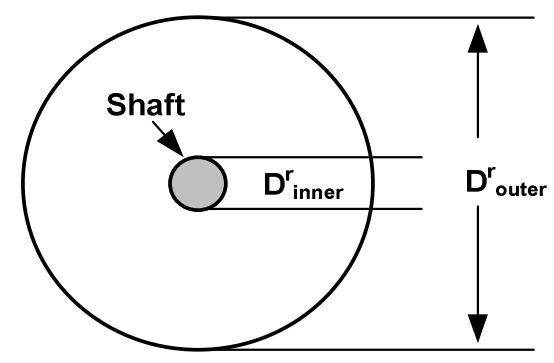

Fig. 3: Rotor core inner and outer diameters.

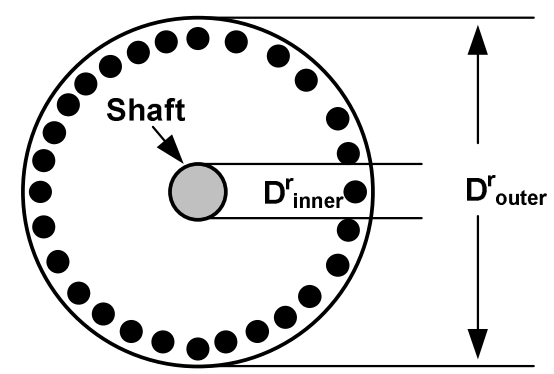

Fig. 4: Squirrel cage rotor core inner and outer diameters.

In addition to synchronous speed, capacity, voltage and current standard values, we have to add dimensions and shapes. For standard dimensions, it is understood, inner and outer stator core diameters, inner and outer rotor core diameters and slot shapes and dimensions; thus, standard ferromagnetic plates can be used.

Recyclable Stator Windings: An induction motor with recyclable stator windings could be designed as follows,

If it is a radically new machine with stator slots, in which windings, based on conventional circular power cables, lie in circular bores. An innovative stator design with slots having cylindrical openings and a unique winding arrangement are at the heart of this new concept. Power cables are threaded through the slots with outside semi conducting layers. The winding cables are flexible and easy to bend, simplifying handling, assembly, disassembly and maintenance. This winding is the simplest and most commonly used not only in AC induction machines but also in synchronous machines as well. The three-phase 4-pole windings configuration has been given. Windings of the kind just described can be specified in a standard manner and construction technologies for mass production may be applied.

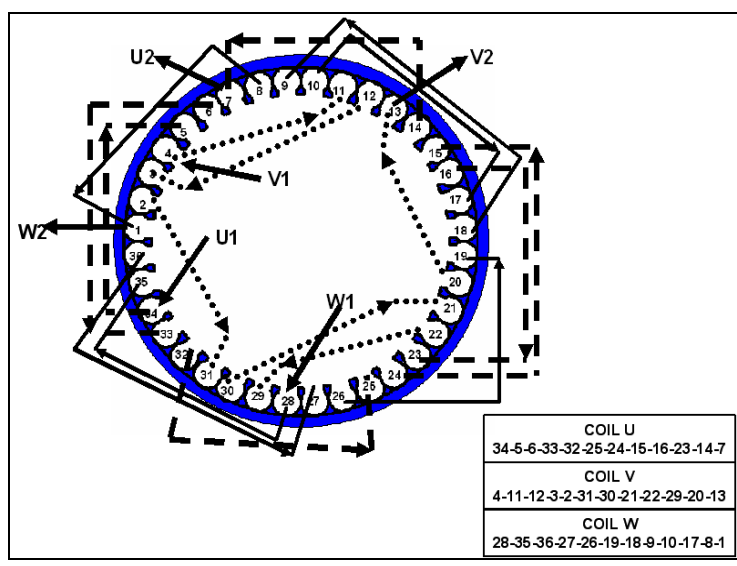

Fig. 5: Three-phase 4-pole windings configuration

Another method also can be applied for AC motor stator winding purposes, it is called an air-gap winding, a bit complicated than previous one. It has a helical winding form, is an air-gap winding having no iron teeth in the active region, employs a limited voltage gradient insulation scheme and is cooled by an insulating fluid. Structurally, the winding employs bonded joints between the conductors and structural tubes, which are of filament-wound fiber-reinforced plastic. ${ }^{[6]}$

\section{MATERIALS AND METHODS}

Cores: All ferromagnetic materials to consider should have among their characteristics the capacity to be regenerated to initial conditions or where aging mechanisms are neutralized. It is obvious, the need for ferromagnetic plates with small or no age tendency, or even better materials whose characteristics improve with aging. These materials should have low losses, minimum contamination, low impurities and being soft and elastic and their electromagnetic induction properties should not to be sacrificed. In general, losses, impurities and plastic deformations accelerate aging and make less effective or complicated, regenerating treatments.

Winding insulation: Insulating winding systems can be treated in two ways:

- In a recyclable induction motor, preferably, insulations materials for windings should "become hard with reversible transformation", and be homogeneous. Hardening with reversible transformation implies that insulators should losses their hardening and recover its properties using relevant treatments. Ideally, windings insulation should be removed easily too. 
- The epoxy resin used on modern induction motors, is an example of hard insulations, this material can be removed, with great difficulty but it has demonstrated long life characteristics.

Electrical insulating varnishes are an important category of protective materials. These coats should be easily removed and regenerated with an appropriate chemical thermal treatment. They are used to coat layer tapes and wrappers, wedges, core plates and other main constructional parts.

Conductors: For iron, copper and aluminum; the industrial system presents an interesting picture. Techniques for recycling these metals are well established, and there is an infrastructure for collecting scrap. However, the greatest end value of a recycled induction machine is obtained when: a) ferromagnetic plates are reused as ferromagnetic plates with equal shapes or even better entire cores are reused and b) coils (metal conductors: copper and aluminium) are reused as coils; or even better, entire windings. Therefore, again, standard dimensions, shapes and capacities ought to be established; and coils must be designed with minimum or no aging tendencies.

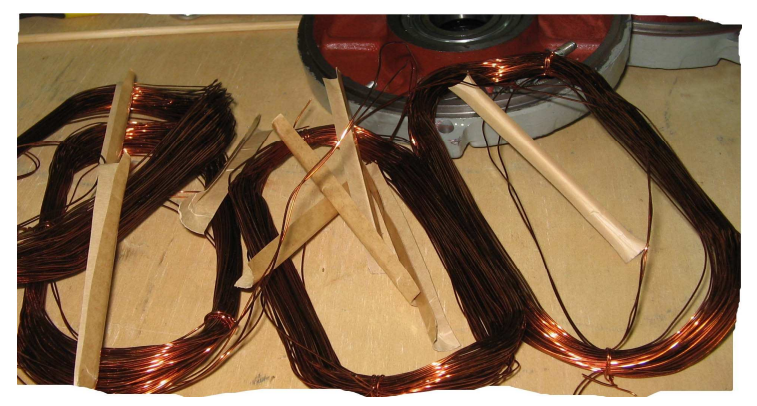

Fig. 6: Recycling Materials

AGING MECHANISMS: Following situations cause aging on induction machines materials and structures:

- Operational aging situations are related to stresses associated to induction machine operation, characterized as temperature, current densities and voltages, peripherical speed, vibration levels, etc causing non reversible chemical reactions, stresses or deformations.

- Non-operational aging situations may cause non-reversible chemical reactions, stresses or deformations too.

In general, reducing operational stress levels: a) increases life, b) facilitates restoration of materials original specifications, and c) diminishes occurrence of irreversible processes.

Thus, design of recyclable induction motors demand analysis of stress levels in an "economic" manner. Induction motor structures deteriorate mainly during operating normal and abnormal conditions. Thermal, electrical and mechanical stresses can cause cracks or deformations or discharges or chemical reactions that destroy the structure integrity. These mechanisms, isolated, are well known, however, composite aging is not well understood. Stress corrosion, partial discharges, vibration levels, mechanical forces and hot spots are just a few examples that combined, cause aging in a manner difficult to predict. Again, standard structures, standard dimensions and standard shapes might allow deeper statistical analysis, allowing in the future, better designs.

\section{Further Work:}

- Patent developments.

- Standard dimensions project.

- Proposals for shape standards.

- Proposals for rotor standards.

- Formulation of robust "economic" methodologies to study design options on electrical machinery construction and suggested data.

- $\quad$ Prototype development and testing.

Drawbacks of Recycling or Take-Back System: The functions of the recyclable key parts/hardware in endof-life of electrical machines have been destroyed by recyclers for the purpose of verification and validation by the inspection and verification committees. The lack of information on product composition, materials and hazardous components prohibit the worker in dismantler plants performing excellent recycling tasks. Therefore, the increasing the cost of recycling tasks and safety problems of the workers. Updating disassembly techniques and equipment for future disassembly tasks, it can be improve the future directions of the recycling guidelines. However, including repair, reuse and remanufacturing plants into the take-back and recycling guidelines are necessary for smooth running of this system. ${ }^{[2]}$

Large Induction Motor Manufacturing For Industrial Demand: Most probably, the future will not see original equipment manufacturers developing induction motor components. Rather we anticipate a world of "modern" cooperation where:

- Component developers as insulation and ferromagnetic sheet producers, coil 
manufactures and core, shaft and frame builders will form partnerships or they will establish strategic alliances to share designs and information for machine developments.

- Original equipment manufacturers will assume the role of integrators.

- There will be intense competition based upon specialized knowledge and large-scale production (free trade based upon international specialization using comparative advantages).

- Low cost component developers will expand their operations to capture and internalize technology.

- Standards, and only standards, will ensure part compatibilities.

- Original equipment manufacturers and component developers will partner with machine users through standards, to optimize testing and to reduce time and overall cost to bring electrical machines into the market.

- There will be mechanisms for acquisition of knowledge (open knowledge). No knowledge monopolies. No dominant knowledge firms.

\section{CONCLUSIONS}

A Recycling based design guidelines for AC induction motors has been proposed and developed. The machine components/hardware has been implemented and tested in the laboratory. The experimental result has been observed to be in worthy. When an induction motor is easily assembled and disassembled, an easily maintained machine is obtained. Furthermore, when an induction motor is built using standard components, maintenance is cost effective too. Therefore, when recycling guidelines are used, reductions on maintenance costs are achieved.
To build recyclable induction motor makes sense when it does "economic" sense. "Economic" means, in this work, overall economic consideration and it does not mean microeconomic evaluation from a manufacturer or a user limited views, that is to say: external costs, real energy and interest costs have to be considered and residual value of an equipment at life end of an installation must be accounted for and society should be viewed as a global one and no from regional perspectives. It hopes to force to electrical machine manufacturers associations worldwide to develop environmentally conscious products with recyclable, easily disassemble, reusable parts and safe materials capabilities. The recycling designed AC induction motor can be used for multiple purposes, no doubt.

\section{REFERENCES}

1. C. Singh, D. Sarkar, 1999. "Practical Considerations in The Optimizations Of Induction Motor Design", IEE Proceedings-B, Vol. 139, No. 4.

2. Jahau Lewis Chen, 2001. "Some Observations on Recycling of Electrical Home Appliance Activities in Taiwan", IEEE.

3. Rafael Hemindez-Millan, Dayco, 2001. "Design Principles For Recycling Induction Motors", PP 782-788, IEEE.

4. MOHAMMAD AYYUB, $S$. S. M URTHY, 2000 "Energy Conservation Through Improved Design Of Induction Motor", Electrical Engineering Department, Indian Institute of Technology, New Delhi, INDIA.

5. V.B. HONSINGER, 1987 "Sizing Equations for Electrical Machinery ", IEEE Trans. on Energy Conversion, Vol. EC-2, no. 1, pp. 116-121.

6. James L. Kirtley Jr. (F), Joseph L. Smith, Jr. (M), Stephen D. Unians (SPUI), 1994. "Ten MVA AirGap Armature Winding: Thermal, Structural And Dielectric Results", IEEE Transactions on Energy Conversion, Vol. 9, No. 2. 